\title{
IoT Based Oil Condition Monitoring of Wind Turbine Gearboxes with Smart Sensor Technology
}

\author{
L. Chitra ${ }^{1}$, V. Ramakrishnan ${ }^{2}$ \\ ${ }^{1}$ Electrical and Electronics Engineering, Sathyabama University, India \\ ${ }^{2}$ Electrical and Electronics Engineering, Madha Engineering College, India
}

\begin{abstract}
Article Info
Article history:

Received Sept 29, 2016

Revised Nov 13, 2016

Accepted Nov 22, 2016

Keyword:
Cantilever
Comb drive
Humidity
IoT
MEMS
Pressure sensor
Thermal actuation
Viscosity

Keyword:

antilever

IoT

Pressure sensor

Viscosity

\begin{tabular}{l} 
Article Info \\
\hline Article history: \\
Received Sept 29, 2016 \\
Revised Nov 13, 2016 \\
Accepted Nov 22, 2016 \\
\hline
\end{tabular}

ABSTRACT

The performance parameters such as viscosity, humidity and pressure of the gear box lubricating oil should be monitored and controlled to improve the efficiency of the windmill. The recent technique like IoT is used for the continuous transmission of bulk data of these parameters from one machine to other machine which is situated in remote locations. Also, the development of mobile technology and web made the live monitoring easier. Thus, transmission and sharing of data takes place without any time delay. The technology also helps to completely eliminate the assistance nearby the site. The large wind farms in coastal areas are easily and continuously monitored and the data are recorded from remote locations with the mobile technology having internet connections. This paper also reports the design of MEMS viscosity sensor, MEMS humidity sensor and MEMS pressure sensor for continuous monitoring of the lubricating system. The main advantage of implementing MEMS devices is to reduce the size and cost and also the sensitivity is improved. Along with IoT, smart sensor technology is also introduced in the monitoring which avoids the serious problems that occur in wind mills.
\end{abstract}

Copyright (C) 2016 Institute of Advanced Engineering and Science. All rights reserved.

\section{Corresponding Author:}

L. Chitra,

Electrical and Electronics Engineering,

Sathyabama University,

Jeppiaar Nagar, Rajiv Gandhi Road, Chennai - 600 119, India.

Email: chithra.research@gmail.com

\section{INTRODUCTION}

The physical web concept along with smart sensor for automation in monitoring of wind turbine led to have an impact on sustainability. Now a days smart grid devices are interconnected with web technology. Each physical device is having unique address. The main advantage of IoT is billions of objects can be connected and monitored at the same time. If control also to be done along with monitoring then bidirectional communication is done for transferring and exchanging the data between the physical objects. The advantage of such a technique is it is more robust and scalable $[1,2]$.

The important function of gear box is to increase rotational speed from a low-speed rotor to a higher speed electrical generator. The lubrication system designed should be reliable so that It can prevent the oil from contaminations and moisture and perform effectively for all the changes in the rotational speeds of the gearbox even during wide changes in temperature. scuffing occurs due to the movement and transfer of small particulates from the teeth which will form unnoticeably due to the breakdown of the lubrication film under heavy loads. The improper maintenance of film thickness also makes cracks on the surfaces which results in micropitting. The factors which maintain the film thickness are speed, load, temperature, roughness and also the chemical composition of the lubricant.

The gearbox which is situated at a height of 300 feet and also installation in rough seas made difficult to access the tower for maintenance and oil draining. currently the oil drain interval is 8 and 12 months. The 
oil maintenance, earlier detection of failure in lubrication and the expectations of the new generation oils in future will extend the drain interval to even six years. The synthetic oils such as PAOs (Poly Alpha Olefin), PAO/ester Blend and PAGs (Polyalkalene Glycol) provide excellent viscosity, longer life, can be used for a wide range of temperature changes, hydrolytically stable and resistance to micropitting.

\section{BASIC ARCHITECTURE OF WECS REMOTE MONITORING}

Wind energy is one of the most important renewable energy sources. Since the cost of maintenance and implementation of windmill is very high, continous monitoring is required. The most serious problems occurs due to the mechanical failure of wind turbine. The most important failures in sensitive regions like gears and gearboxes are susceptible to faults which mainly affect the production of energy in wind turbines. Hence we reduce the fault and failures of the moving object such as gear boxes by introducing smart technology in continuous monitoring [3, 4].

The problem in gear box leads to other electrical and mechanical faults in generators, grids or electrical system and the converter section. The monitoring of all the parameters using IoT provides security from the electrical and mechanical faults. The block diagram of the architecture of wind energy conversion system with monitoring as shown in Figure 1.

A wind turbine is a device that converts the winds kinetic energy into electrical power. Wind turbine is made up of different components used for the conversion of electrical energy. Gear box in wind turbine is used to increase the rotational speed and then connected to the higher speed electrical generator. The rotor blades which are exposed to wind, forces to start rotation of the blade. As the rotor spins, the shaft also rotates with the same speed $[5,6]$.

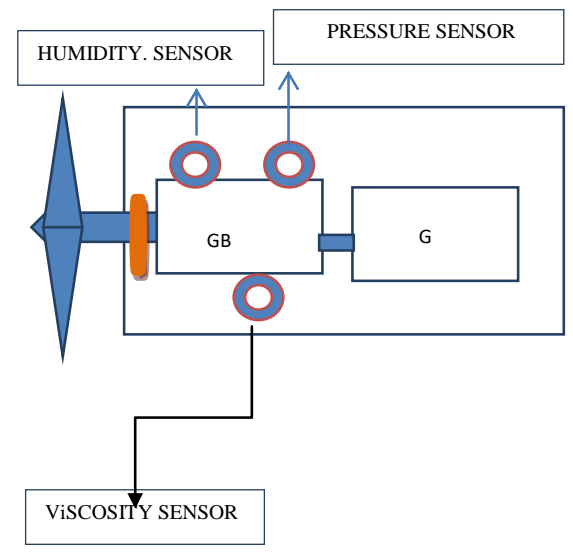

Figure 1. The Architecture of Wind Energy Conversion System with Monitoring Devices

The gearbox now converts the slow speed into a faster rotating speed. Then it is connected to the generator. Various sensors such as viscosity sensor, humidity sensor and pressure sensor were used in the gearbox for oil condition monitoring. Using IoT, the sensors are connected and also monitored. The connected devices which enables remote monitoring and transmission of information between machine to machine communications.

\section{BLOCK DIAGRAM OF IOT BASED MONITORING SYSTEM}

Using IoT, the physical devices such as humidity sensor, pressure sensor and viscosity sensor are connected with the internetwork and the necessary electronics, software, sensors were embedded and the information between the physical devices were transferred and exchanged. The block diagram of IoT based monitoring system is as shown in Figure 2.

The implemented system consists of a microcontroller (ATmega328) as a main processing unit for the entire system and all the sensor and devices can be connected with the microcontroller. The sensors can be operated by the microcontroller to retrieve the data from them and it processes the analysis with the sensor data and updates it to the internet through Wi-Fi module connected to it $[7,8]$. 


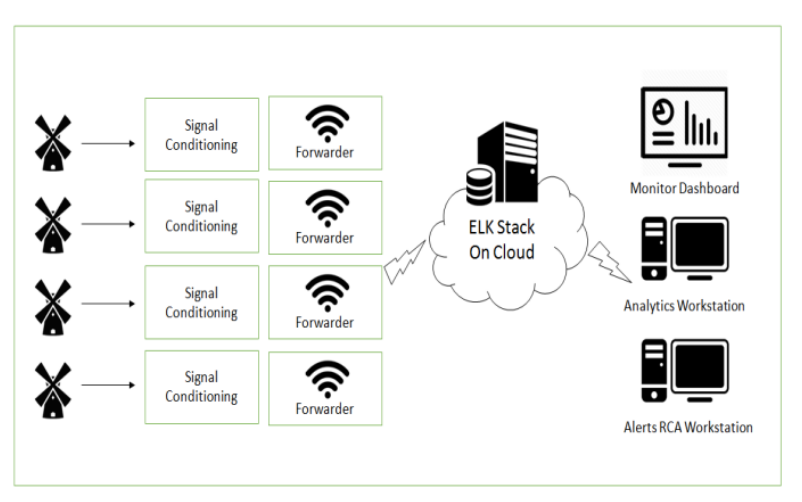

Figure 2. Block Diagram of IoT Based Monitoring System

The system designed consists of a microcontroller cortex-M4 CC 3200 as a main processing unit and the sensors such as viscosity, humidity and pressure are connected to themicrocontroller. The high performance CC3200 is the first single chip microcontroller with built in Wi-Fi connectivity for the Launch Pad TM system. This simple Wi-Fi CC3200 device is a wireless microcontroller that integrates a high performance ARM Cortex M4 microcontroller allowing customers to develop an entire application with a single IC. The CC3200 Launch Pad is a low cost evaluation platform for ARM CortexTM M4F-b and microcontroller. This Launch Pad highlights about the Internet on a chip solution and Wi-Fi capabilities. The expansion of launch pad can increase the interfaces such as graphical displays, environmental sensing and more. The block diagram of monitoring system as shown in Figure 3.

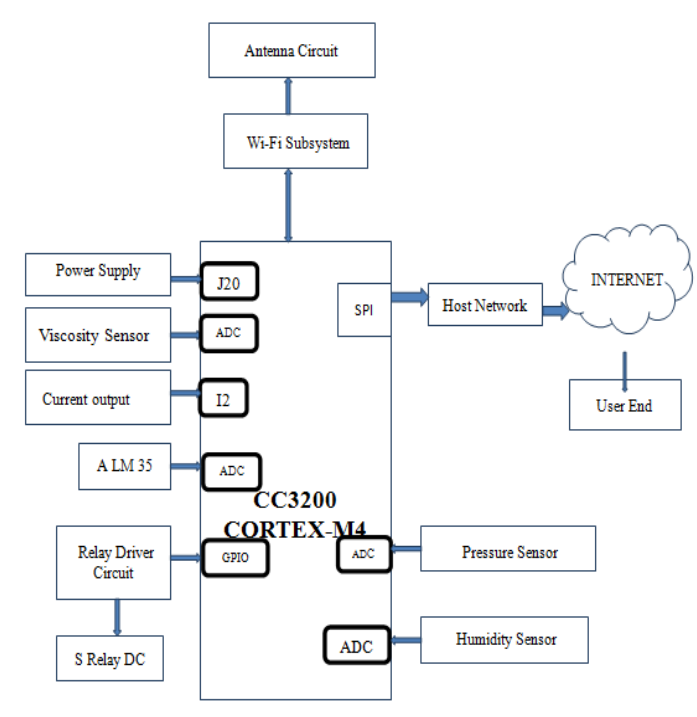

Figure 3. The Block Diagram of Monitoring System

IoT - Blynk cloud is a platform with IOS and android apps to control IoT development boards. It is also used to control ardino and Raspberry pi. It is digital dahboard where you can build a graphic interface for your application by simply dragging and dropping widgets.

\section{DESIGN OF VISCOSITY SENSOR}

The viscosity of the lubricating oil is measured with a help of Micro Electro Mechanical systems (MEMS) based viscosity sensor [9, 10]. The design of the sensor as shown in Figure 4. 


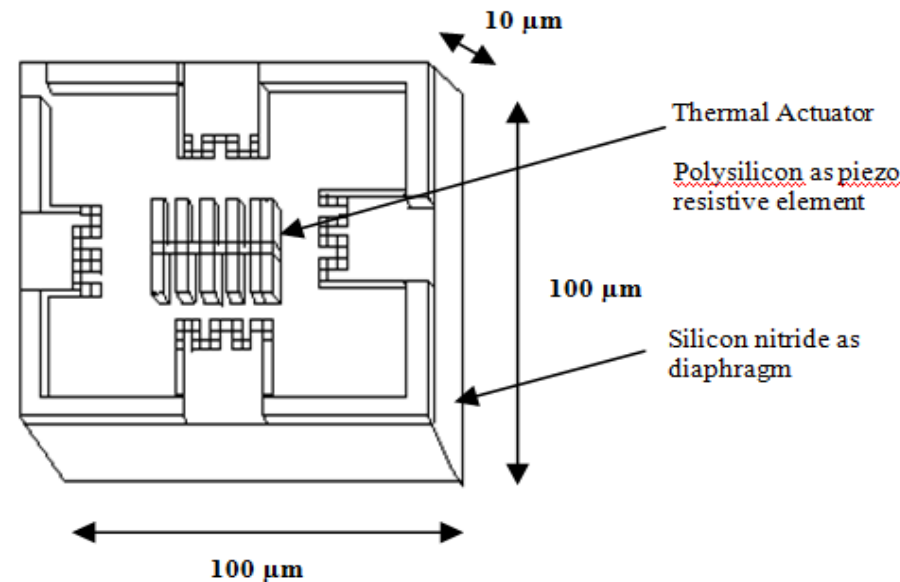

Figure 4. The Layout of the Viscosity Sensor

The diaphragm made up of silicon nitride is acting as the sensing medium. A thermal actuator made up of polysilicon and PSG is placed over the diaphragm. Initially the thermal actuator generates vibration because of the application of current the frequency of oscillation is measured [11].

The viscous force generated in the fluid interact with the diaphragm and the excited thermal actuator will vibrate and the force generated interacts with the force generated by the viscosity of the fluid the net displacement of the diaphragm is measured with the piezoresistor and the corresponding output will be directly proportional to the viscosity of the fluid. The piezoresistor is made up of polysilicon. The variation of the potential as shown in the Figure 5.

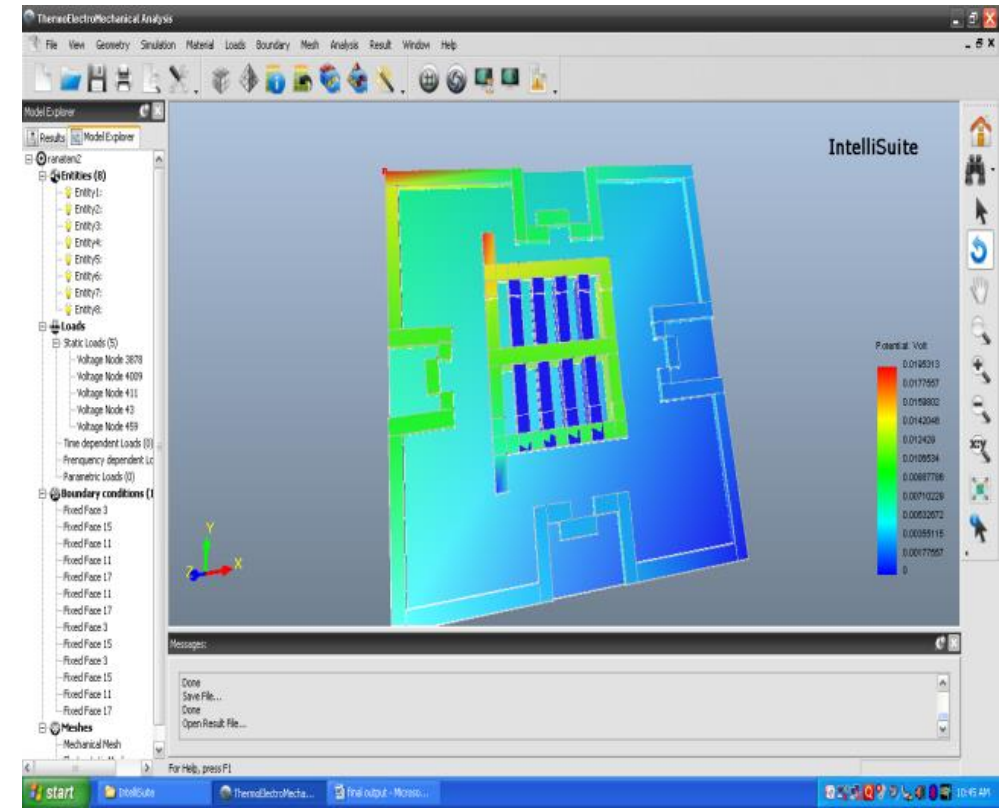

Figure 5. Variation of Potential Due to Change in Viscosity

\section{DESIGN OF HUMIDITY SENSOR}

The structure of the sensor is a cantilever type which is coated with a layer of graphene oxide on the copper substrate. The designed humidity sensor as shown in Figure 6. The sensitive layer absorbs the humidity and so the mass of the cantilever increases which in bends the cantilever. 


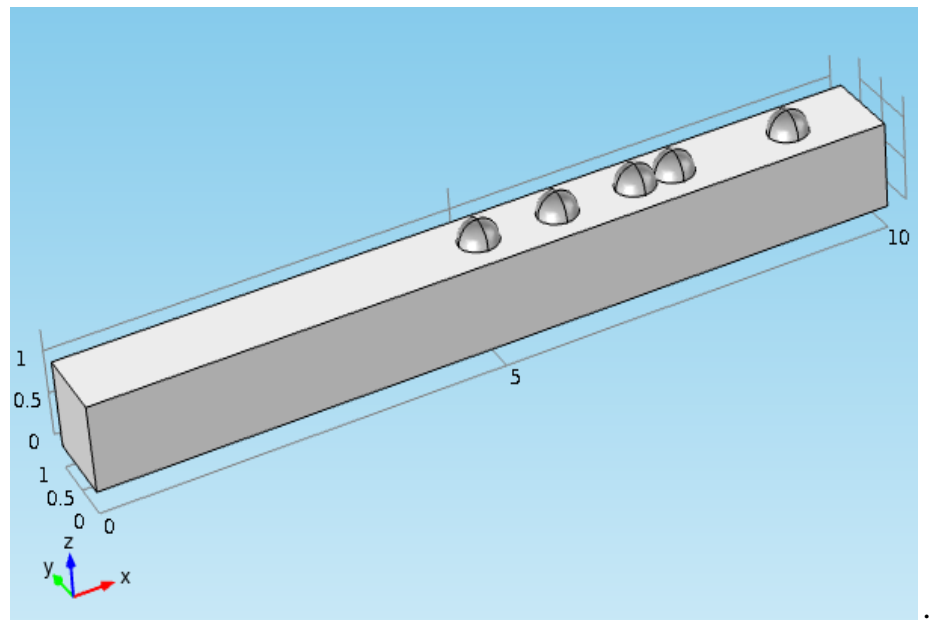

Figure 6. Cantilever Type Humidity Sensor

The displacement profile of the cantilever type humidity sensor is analysed and shown in Figure 7. Simulation of the paddle shaped humidity sensor is analysed using comsol Multiphysics. The moisture content absorbed is calculated using gravimetric method. The weight of the wet sample and dry sample is found and then calculated the percentage of humidity absorbed by the graphene oxide film. The fabrication of this type of humidity sensor is easy and the cost is also reduced.

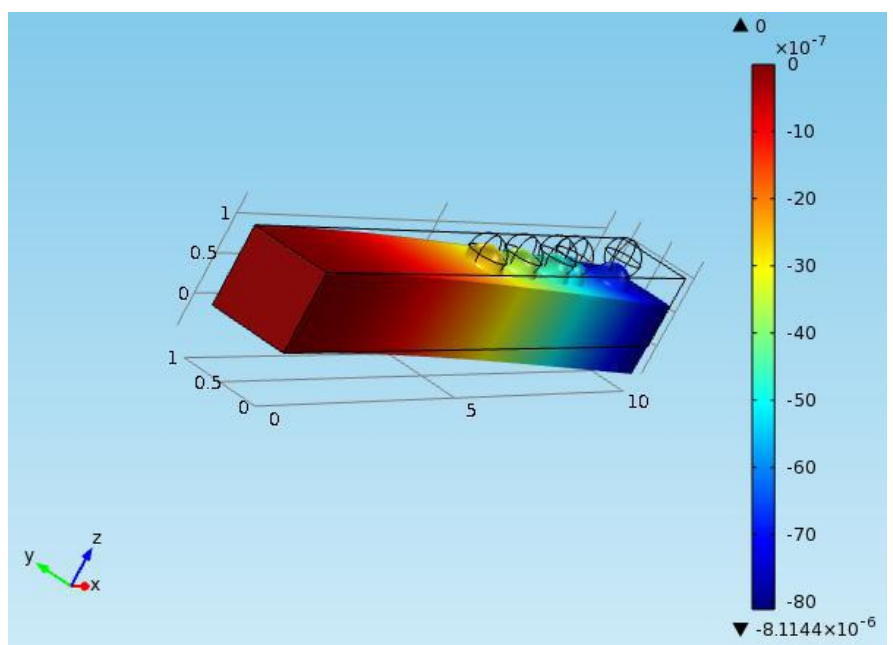

Figure 7. Displacement Analysis Using Comsol Multiphysics

\section{DESIGN OF MEMS PRESSURE SENSOR}

The pressure measurement is the most important parameter to be done for oil analysis. A novel technique is used for the measurement of pressure [11]. There are two plates upper and lower plate fabricated with comb structure on either side of the plates. The sensitivity of the structure is improved by connecting a diaphragm to the movable plate [12]. The diaphragm is coupled to the movable plate. When the oil pressure changes, the diaphragm gets deflected and the movable plate also gets deflected. The change in distance between the plates causes the capacitance to change. The change in capacitance is proportional to the pressure generated in the oil $[13,14]$.

The device is said to be more sensitive since any smallest change in the pressure is measured by the diaphragm [15]. The diaphragm is having direct contact with the pressure sensing medium. The structure of the pressure sensor as shown in Figure 8. 


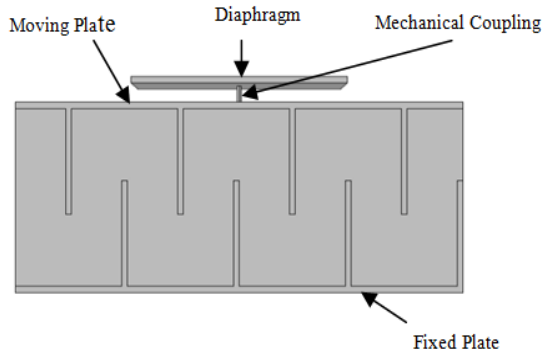

Figure 8. MEMS Pressure Sensor

The upper and the lower comb plate is made up of gold and the diaphragm is made up of Aluminium. The simulation model was fabricated using comso multiphysics. The analysis is done by applying pressure to the design. The displacement profile of the movable plate and the diaphragm as shown in Figure 9.

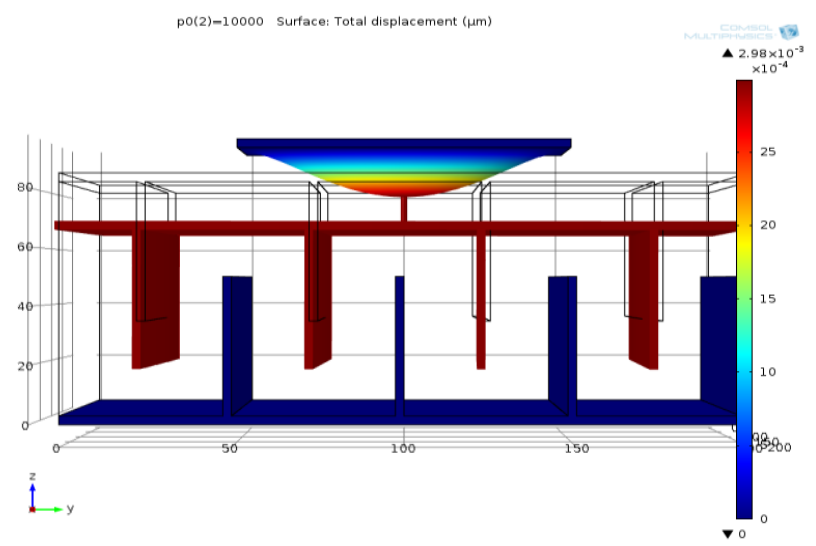

Figure 9. Pressure Analysis Using Comsol Multiphysics

\section{RESULTS}

The continuous monitoring of the windmill reduces the downtime and losses due to damage ensured by the system. The system for monitoring is thus designed and the embed is interfaced to sensors. The status of the monitoring system is displayed automatically and the fault is automatically sent to the Gmail account also. This automatic monitoring system when combined with IoT based data base, is used to access the real time data from anywhere with only the cellphone app. Thus the energy efficiency is improved and also proper maintenance of the system is installed due to early, fast and real time fault detection and diagnosis. Also the sensors damages, expensive repair and production losses can be avoided. Smart Windmill Gear box monitoring system is done using mobile application as shown in Figure 10.

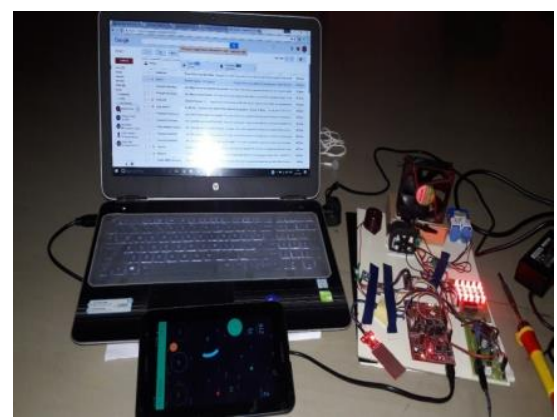

Figure 10. Smart Windmill Monitoring System 
It consists of an embedded system which is interfaced to sensors and other control devices for monitoring and also be controlled. The necessary data such as viscosity, humidity and pressure of the lubricating system is monitored and any deviation in the value occurring in the system is monitored in the mobile as well as automatically it will give a buzzer sound. The monitoring done using mobileapp as shown in Figure 11.

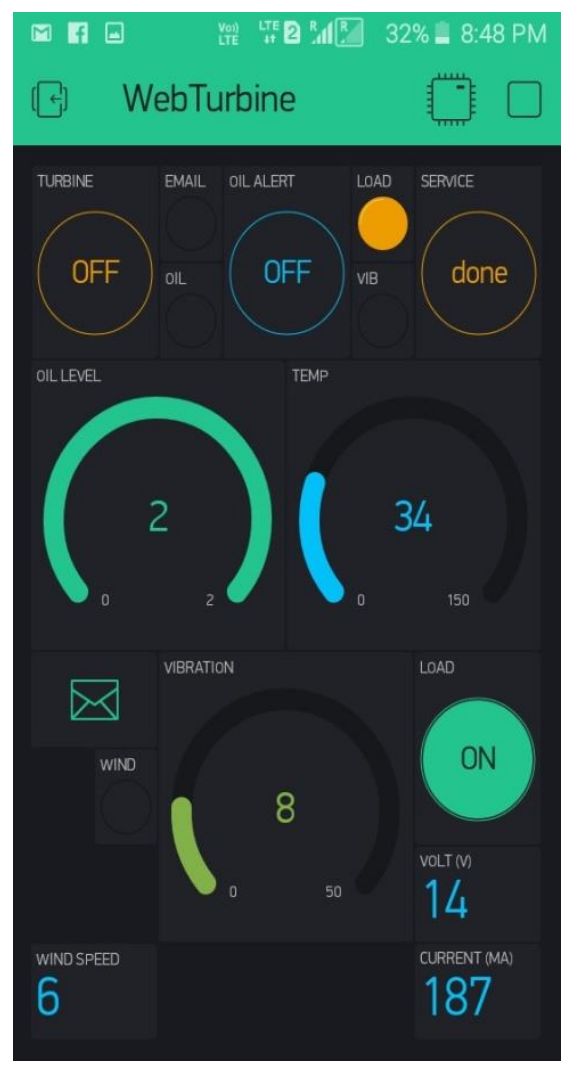

Figure 11. Smart Wind Turbine Monitoring Using Mobile App

The complete details and status of the system will be automatically sent to Gmail also. The screen shot of the mail received during abnormalities as shown in Figure 12.

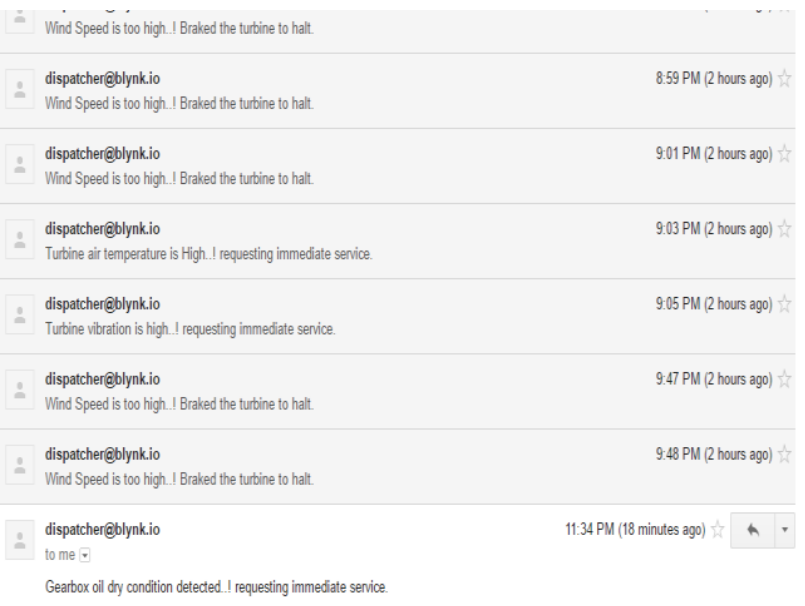

Figure 12 Screenshot of the Mail Received During Abnormalities 
With the help of this, it is easy for us to monitor the performance of the windmill. Also monitoring can be done anywhere since the data is continuously transferred to the mobile we can also include many parameters for monitoring using this system. So IoT based remote monitoring will improve energy efficiency of the system. The implementation of this application help us to have an easy and fast real time monitoring so that early detection of serious problem in lubricating system is also possible.

\section{CONCLUSIONS}

Internet of things is a physical transfer of information taking place between machine to machine and also between person to computer.Thus IoT is correlated with smart sensor technologies such as WSN, Nanotechnology and miniaturaization. The rapid advancement in internet Technologies are utilized for the monitoring of parameters of Gear box Lubricating system. The increase in users of internet due to advancement of internet connected mobile devices such as smart phones and tablets enables the networking of everyday objects.

\section{REFERENCES}

[1] Soham Adhya, Dipak Saha, Abhijit Das, joydip Jana, and Hiranmay Saha, "An IoT Based Smart Solar Photovoltaic Remote Monitoring and Control Unit," Proceedings of International conference on control, Intrumentation, Energy and Communication IEEE CIEC'16, pp. 432-436, 2016.

[2] Uma Gurav and Chandradeep Patil, "IoT Based Interactive Controlling and Monitoring System for Home Automation," International Journal of Advanced Research in Computer Engineering \& Technology (IJARCET), vol. 5, no. 9, 2016.

[3] J. Ribrant, "Reliability Performance and Maintenance - A Survey of Failure in Wind Power Systems," Master thesis, KTH schoolof Electrical Engineering, 2006.

[4] M. Mohsin Khan, et al., "Reliability and Condition Monitoring of a Wind Turbine," Proceedings of IEEE CCECE'05, Saskatoon (Canada), 2005.

[5] I. Albizu, et al., "Online Stator Winding Fault Diagnosis in Induction for Renewable Generation," Proceedings of IEEE MELECON'04, Dubrovnik (Croatia), vol. 3, pp. 1017-1020, 2004.

[6] P. Caselitz, et al., "Development of a Fault Detection System for Wind Energy Converters," Proceedings of EUWEC'96, Goteborg (Sweden), pp. 1004-1007, 1996.

[7] S. Li, L. Xu, X. Wang and J. Wang, "Integration of Hybrid Wireles Networks in Cloud Services Oriented Enterprise Information Systems," Enterp.Inf.Syst, vol. 6, no. 2, pp. 165-187, 2012

[8] Asif Saced, "Online Condition Monitoring System for Wind Turbine Case Study," Master Thesis, University of Kalmar, Blekinge Institute of Technology, 2008.

[9] L. Chitra and Dr. V. Ramakrishnan, "Design Optimization of Piezoresistive Multi MEMS Device for Lubricating System," Advances in Natural and Applied Sciences, vol. 8, no. 21, pp. 76-84, 2014.

[10] L. Chitra and Dr. V. Ramakrishnan, "Comparative Analysis of Cantilever Device for MEMS Device for Humidity Measurement," Elysium journal of engineering research and management, 2014.

[11] L. Chitra and Dr. V.Ramakrishnan, "A Novel Design of Capacitive MEMS Pressure Sensor for Lubricating System," NCETNRES EM 2014, IEEE Conference Publications, 2014.

[12] S.M. Firdaus, I. A. Azid, O. Sidek, K. Ibrahim, and M. Hussien, "Enhancing The Sensitivity of a Mass-Based Piezoresistive Micro-Electro-Mechanical Systems Cantilever Sensormicro \& Nano Letters," IET, Apr 2010.

[13] S. Roy, T. Majhi, S. Sinha, C.K. Sarkar, and H. Saha, "Electro Thermal Analysis and Fabrication of Low Cost Microheater Using a Nickel Alloy for Low Temperature MEMS Based Gas Sensor Application," International Conference on Industrial Electronics, Control \& Robotics (IECR), 2010.

[14] Y. Wahab, A. Zayegh, and R. Begg, "Silicon Implementation of Micro Pressure Sensor Electronic Devices," Systems and Applications (ICEDSA), 2010.

[15] M. T. Lazarescu, "Design of a WSN Platform for Long-Term Environmental Monitoring for IoT Applications," IEEE J. Emerg. Sel. Topics Circuits Syst., vol. 3, no. 1, pp. 45-54, 2013. 